\title{
Uso do Efluente Sanitário na Indústria Cerâmica
}

\author{
Alexsandro Bona, Simone Soares Göhringer, Miguel Mansur Aisse \\ Centro Politécnico - UFPR \\ alexsandro.bona@gmail.com, andreasg@bighost.com.br, miguel.dhs@ufpr.br
}

Recebido: 21/08/07 - revisado: 26/09/07 - aceito: 13/02/08

\begin{abstract}
RESUMO
A ETE Cambui da SANEPAR recebe esgotos sanitários e emprega fluxograma de tratamento, incluindo reator tipo $R A L F$, tratamento físico-químico com flotação por ar dissolvido e desinfecção. Este trabalho contemplou o uso não potável do efluente da ETE Cambuí, na Indústria Cerâmica do Município de Campo Largo-PR. Sua vazão de projeto é 100L/s e foi escolhida pela qualidade do efluente tratado e localização. Os efluentes foram avaliados em duas indústrias, INCEPA $e$ Lorenzetti, ambas produzindo materiais cerâmicos, situadas próximas a ETE. O estudo iniciou-se com a avaliação da demanda de água não potável, destacando-se o consumo nos moinhos de matérias-primas. A utilização do efluente foi conduzida na INCEPA, em escala industrial, resultando na confecção de peças cerâmicas (azulejos e pisos), sendo aceitas para comercialização. Os ensaios na Lorenzetti foram realizados em escala piloto, empregando paralelamente água e efluente. Os corpos de prova produzidos foram submetidos a ensaios específicos para produtos eletro-cerâmicos e mostraram comportamentos idênticos. Conclui-se que é possível utilizar o efluente tratado e desinfetado da ETE Cambuí para fins não potáveis, atuando assim no conceito de "substituição de fontes". Foram também elaborados cenários de utilização de efluentes para outros usos, com possibilidade de uso de até 41,4\% de efluente.
\end{abstract}

Palavras-chave: Campo Largo - PR; efluente sanitário; indústria cerâmica; reúso da água; uso não potável.

\section{INTRODUCÃ̃O}

A utilização planejada de reúso de efluentes, em todo o mundo, tem sido bastante incrementada nas últimas décadas, como resposta à escassez dos recursos hídricos disponíveis. Inúmeras cidades e regiões metropolitanas têm recorrido ao reúso da água, obtida a partir da utilização dos efluentes das estações de tratamento de esgotos, complementando as demandas para fins urbanos, industriais e atendimento do setor de serviços (SEMURA et al., 2005).

O reúso para fins não potáveis tornou-se uma opção viável para complementar os mananciais públicos de água, em regiões semi-áridas dos Estados Unidos e de outras regiões do mundo. Durante a seca de 1976-77 na Califórnia, quando a escassez de água pressionou os consumidores a ponto de formalizarem propostas para o consumo de água recuperada, ocasião em que foi enfatizado o potencial de uso do esgoto tratado para uma variedade de propósitos. A Califórnia foi responsável pelos primeiros critérios de qualidade, encorajando engenheiros e comunidades a assumirem o reúso não potável. O impacto desta e de outras atividades associadas aumentou o uso da água reciclada para fins não potáveis (Crook, 1991).

Crook (1991) cita a experiência de aproximadamente 115 operações de irrigação, 9 aplicações de reúso industrial, 13 represas paisagísticas ou recreacionais e 2 barreiras contra intrusão de cunhas salinas, utilizando água residuária reciclada.

A bacia do Alto Tietê, que abriga uma população superior a 15 milhões de habitantes e um dos maiores complexos industriais do mundo, dispõe, pela sua condição característica de manancial de cabeceira, tem vazões insuficientes para atende a demanda da região metropolitana de São Paulo e dos municípios circunvizinhos. Nestas condições, o conceito de "substituição de fontes" mostra-se como a alternativa mais plausível para satisfazer as demandas menos restritivas, liberando as águas de melhor qualidade para usos mais nobres, como o abastecimento doméstico. As águas de qualidade inferior, tais como esgotos, particularmente os de origem doméstica, águas de chuva, águas de drenagem agrícola e águas salobras, devem, sempre que possível, ser consideradas como fontes alternativas para usos menos restritivos. 
O uso de tecnologias apropriadas para o desenvolvimento dessas fontes constitui, hoje, em conjunção com a melhoria de eficiência do uso e o controle da demanda, a estratégia básica para a solução do problema da falta de água (HESPANHOL, 2003).

O presente trabalho contemplou o estudo do uso não potável de efluentes de Estações de Tratamento de Esgotos - ETE's na Indústria Cerâmica, buscando os seguintes objetivos específicos: estudar o uso do efluente da ETE Cambuí na Indústria INCEPA; estudar o uso do efluente da ETE Cambuí na Indústria Lorenzetti; e estudar a confecção de peças cerâmicas utilizando efluente sanitário tratado.

\section{HIPÓTESE}

É possível empregar-se efluente sanitário tratado e desinfetado para uso não potável na indústria cerâmica, sem que a qualidade dos produtos seja afetada.

\section{Materiais e métodos}

\section{Unidade experimental}

Os efluentes foram obtidos da ETE Cambuí da SANEPAR (Companhia de Saneamento do Estado do Paraná), a qual emprega como fluxograma: tratamento preliminar; reator anaeróbio tipo RALF; tratamento físico-químico com flotação por ar dissolvido e desinfecção. Sua vazão de projeto é de 100L/s. A ETE está localizada no Município de Campo Largo - PR e foi escolhida em virtude da qualidade do efluente tratado e da tecnologia utilizada.

Os efluentes desinfetados foram avaliados em duas indústrias, INCEPA e Lorenzetti, ambas produzindo materiais cerâmicos e situadas em Campo Largo, próximas a ETE. A INCEPA, atuando na área de revestimentos e pisos cerâmicos, possui duas plantas e utiliza como matéria-prima basicamente a argila, caulins, quartzo e água. A Lorenzetti é fabricante de componentes elétricos de alta e baixa tensão e utiliza como matéria-prima argila, talco, quartzo, feldspato, filito e a calcita.

\section{Delineamento experimental}

Desde o primeiro contato, as Empresas (INCEPA e Lorenzetti) mostraram-se bastante receptivas e interessadas no projeto de pesquisa mencionado, disponibilizando suas instalações e pessoal especializado para trabalho em conjunto com a equipe universitária (Ver Figura 1). Para tanto, procedeu-se a integração das equipes envolvidas, estudando-se o consumo da água na atividade industrial e as possibilidades de substituição de fontes.

Foram elaborados fluxogramas das águas (balanço hídrico), a partir de visitas técnicas orientadas, observando o processo e colhendo informações divulgadas pelas Empresas. Com os fluxogramas procurou-se identificar possíveis pontos de uso não potável do efluente, nos processos industriais.

Amostras de efluente tratado e desinfetado da ETE Cambuí foram coletadas para caracterização físico, química e biológica para orientar a realização dos testes de aplicabilidade do efluente. Os testes foram realizados em escala piloto (na Lorenzetti) e em escala real (na INCEPA).

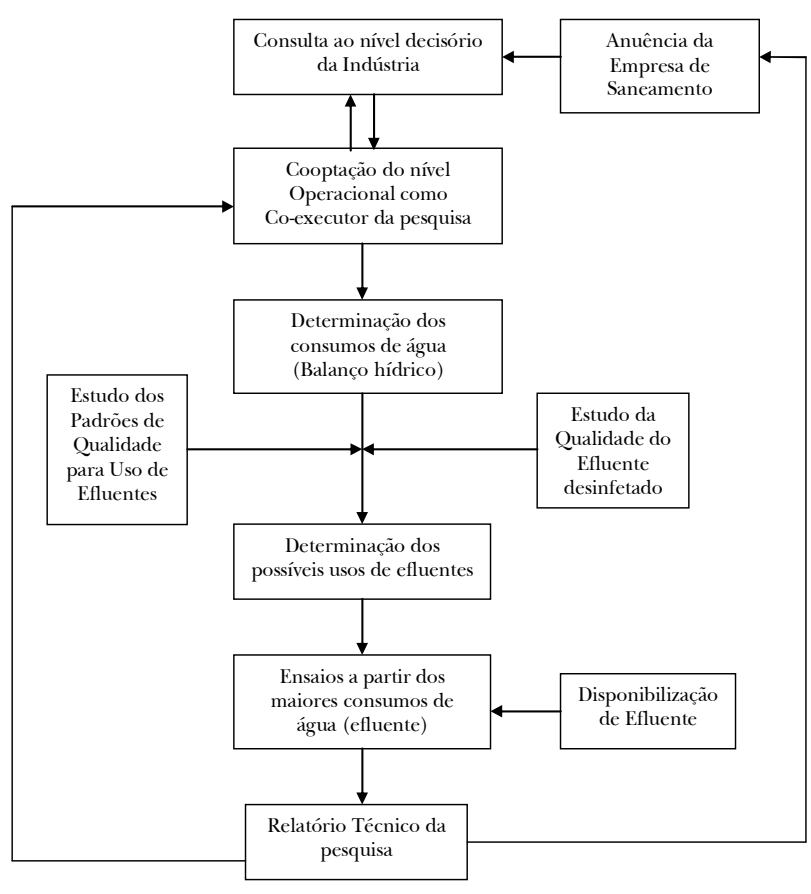

Figura 1 - Diagrama Conceitual da Abordagem do Uso de Efluentes na Indústria

Configuraram-se também cenários referentes às possibilidades de substituição de fontes de água ora utilizadas pela Empresa Lorenzetti e pela INCEPA. Sendo assim, foi considerado passível de substituição, todo o montante utilizado no processo industrial, em limpeza de pisos e equipamentos, hidrantes, bem como o de uso nos vasos sanitários, o qual, para a Lorenzetti foi estimado. 
Relação das metodologias utilizadas

As análises do efluente foram realizadas no Laboratório de Análises Ambientais da PUCPR e observam o descrito no Standard Methods (APHA et $a l ., 1998)$. As amostras pontuais foram coletadas na saída da ETE, incluindo a desinfecção.

As análises do material cerâmico foram realizadas pelas empresas, haja vista que pertencem às suas rotinas de trabalho para homologar a matériaprima que seguirá no processo. Dentre as análises comuns a ambas, destacam-se: densidade aparente, viscosidade e análise de resíduo. Estas são realizadas imediatamente após o descarregamento da massa do moinho, denominada barbotina.

No caso da Lorenzetti, os ensaios na massa e nos corpos de prova, nos quais se utilizou esgoto, foram repetidos em paralelo empregando água de uso habitual no processo industrial, ambos realizados no Laboratório de Ensaios Físico-Químicos. Em se tratando de produtos eletro-cerâmicos, foram necessárias análises específicas realizadas em corpos de prova, simulando cada etapa da confecção de peças, em escala real. Estes foram submetidos a ensaios como perda ao fogo, absorção (fucsina), deformação, umidade, índice piroplástico, ruptura, tanto para o corpo de prova cru, calcinado e com vidrado.

\section{RESULTADOS}

\section{A. INCEPA}

O estudo da demanda de água para substituição por esgoto tratado revelou o processo industrial, em especial a moagem e o corte de peças, como grandes consumidores (Tabela 1).Elegeu-se por facilidades operacionais e por oferecer menor risco aparente, a moagem, quando é introduzida água juntamente com a matéria prima diretamente nos moinhos, para preparação da massa líquida (barbotina), a qual após passar por vários processos, dá origem aos azulejos (Figura 2).

Foram realizados três ensaios, todos em escala industrial, de modo a avaliar o comportamento reológico da massa utilizando esgoto tratado e desinfetado, o qual foi transportado por meio de caminhões-pipa.
Tabela 1 - Avaliação dos consumos de água na INCEPA

\begin{tabular}{|l|c|}
\hline Uso & $\begin{array}{c}\text { Volume } \\
\left(\mathrm{m}^{3} / \mathrm{mês}\right)\end{array}$ \\
\hline$\bullet$ Administrativo & 142 \\
\hline Creche & 15 \\
\hline Ambulatório & 1.882 \\
\hline Banheiros & 648 \\
\hline Refeitório & 2.687 \\
\hline Total & \\
\hline$\bullet$ Processo Industrial & 2.900 \\
\hline Moagem & 3.700 \\
\hline Corte peças & 380 \\
\hline Esmaltação & 6.980 \\
\hline Total & \\
\hline$\bullet$ Outros Usos & 4.936 \\
\hline $\begin{array}{l}\text { Limpeza (pisos e equipamen- } \\
\text { tos) }\end{array}$ & 524 \\
\hline Torre de resfriamento & 5.460 \\
\hline Total & 15.127 \\
\hline Total Geral &
\end{tabular}

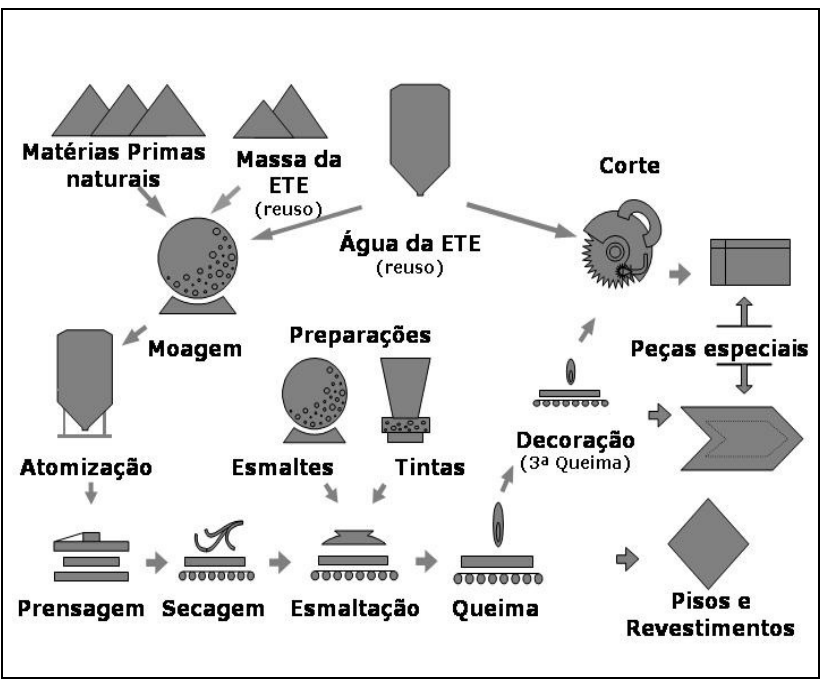

Figura 2 - Fluxograma esquemático da INCEPA

Ensaio 1: A massa foi preparada para a fábrica I, em um único moinho de capacidade para $3 \mathrm{~m}^{3}$ de efluente (Ver Tabela 2), sendo que a matéria-prima foi a de uso habitual da empresa. A moagem realizada dia 28/04/05 totalizou 5,7 horas e após a sua conclusão, foi retirada uma amostra (barbotina) para a realização dos testes de viscosidade, densidade e análise de resíduos (Tabela 3). 
Tabela 2 - Caracterização do efluente da ETE Cambuí utilizado na INCEPA

\begin{tabular}{|c|c|c|c|}
\hline Análises & Tipo & Un. & Média \\
\hline \multirow{14}{*}{$\begin{array}{l}\text { Físico - } \\
\text { químicas }\end{array}$} & $\begin{array}{l}\text { Desinfetan- } \\
\text { Residual }\end{array}$ & $\mathrm{mg} / \mathrm{L}$ & $1,06(2)$ \\
\hline & Alcalinidade & $\mathrm{mg} / \mathrm{L}$ & $204,49(3)$ \\
\hline & DQOt & $\mathrm{mg} / \mathrm{L}$ & $100(5)$ \\
\hline & N-total & $\mathrm{mg} / \mathrm{L}$ & $51,85(4)$ \\
\hline & $\mathrm{N}-\mathrm{NH}_{3}$ & $\mathrm{mg} / \mathrm{L}$ & $38,32(1)$ \\
\hline & $\mathrm{pH}(1)$ & - & $6,4(4)$ \\
\hline & $\mathrm{P}-\mathrm{PO}_{4}$ & $\mathrm{mg} / \mathrm{L}$ & $3,89(2)$ \\
\hline & ST & $\mathrm{mg} / \mathrm{L}$ & $439(4)$ \\
\hline & SST & $\mathrm{mg} / \mathrm{L}$ & $82(4)$ \\
\hline & SSV & $\mathrm{mg} / \mathrm{L}$ & $51(4)$ \\
\hline & SDV & $\mathrm{mg} / \mathrm{L}$ & $92(4)$ \\
\hline & SSed & $\mathrm{mL} / \mathrm{L}$ & $2,1(4)$ \\
\hline & Turbidez & UT & $100(4)$ \\
\hline & Cor & $\mathrm{UC}$ & $107(2)$ \\
\hline \multirow{2}{*}{ Biológicas } & $\begin{array}{l}\text { Coliformes } \\
\text { Totais }\end{array}$ & $\begin{array}{l}\mathrm{NMP} / \\
100 \mathrm{~m} \\
\mathrm{~L}\end{array}$ & $\begin{array}{l}\text { ausentes } \\
(4)\end{array}$ \\
\hline & Escherichia coli & $\begin{array}{l}\text { NMP/ } \\
100 \mathrm{~m} \\
\mathrm{~L}\end{array}$ & $\begin{array}{l}\text { ausentes } \\
(4)\end{array}$ \\
\hline \multirow{2}{*}{ Temperatura } & $\mathrm{Ar}$ & ${ }^{\circ} \mathrm{C}$ & $21(4)$ \\
\hline & Amostra & ${ }^{\mathrm{o}} \mathrm{C}$ & $22(5)$ \\
\hline
\end{tabular}

Nota: ( ) Número de amostras usadas para cálculo da média.

Ensaio 2: O efluente desinfetado foi coletado no dia 13/05/05 (Tabela 2) e imediatamente levado à Empresa para efetuar o teste, sendo reservados dois moinhos, para a fábrica II, cada moinho carregado com $3 \mathrm{~m}^{3}$ de efluente e matéria-prima. A receita preparada no moinho diferia do ensaio 1 , pois devido às diferenças no processo de queima, é usado menos aditivo que para o processo da fábrica I. Após 7 horas de moagem, constatou-se que os moinhos não descarregaram e que a viscosidade estava alta, embora se enquadrasse dentro da faixa de trabalho. Os demais testes estavam com resultados dentro do especificado (Tabela 3 ).

Ensaio 3: Foi realizado no dia 23/11/05 para a fábrica II, também em escala de produção. Para tanto, foram utilizados cerca de $6 \mathrm{~m}^{3}$ de esgoto tratado e desinfetado, neste dia com dióxido de cloro (Ver Tabela 2). Após serem realizadas as correções do $\mathrm{pH}$ do efluente, para próximo de 7,0, foram abastecidos os dois moinhos reservados para o teste. A moagem, com 6,5 horas, produziu a barbotina, submetida a uma peneira de "mesh \#100" e armazenada em um tanque. Neste terceiro ensaio, foi dada continuidade no processo para confecção de peças cerâmicas, até o final da linha de produção.

Tabela 3 - INCEPA - Resumo dos ensaios na barbotina.

\begin{tabular}{|l|l|l|l|}
\hline Origem & $\begin{array}{l}\text { Visc. } \\
(\mathrm{s})\end{array}$ & $\begin{array}{l}\text { Dens. } \\
(\mathrm{g} / \mathrm{L})\end{array}$ & $\begin{array}{l}\text { Resíduos } \\
(\%)\end{array}$ \\
\hline Especificação & $<91$ & $>1.710$ & $4 \mathrm{a} 6$ \\
\hline Ensaio 01 & 43 & 1.729 & 5,29 \\
\hline Ensaio 02 & 87 & 1.731 & 4,53 \\
\hline Ensaio 03 & 39 & 1.738 & 4,54 \\
\hline $\begin{array}{l}\text { Média da Produ- } \\
\text { ção (Ensaio 03) }\end{array}$ & 46 & 1.729 & 5,16 \\
\hline
\end{tabular}

No dia 24/11/05 a barbotina foi recalcada para a secagem no "Spray-Dryer", formando então os grânulos com 6,8\% de umidade média. Foi comparada a granulometria do ensaio com a granulometria obtida na produção com água de uso habitual. Observou-se que os resultados estavam muito próximos (Tabela 4).

Tabela 4 - INCEPA: Distribuição granulométrica da massa granulada

\begin{tabular}{|l|l|l|}
\hline Malha (mm) & $\begin{array}{l}\text { Ensaio 3 (\%) } \\
(1)\end{array}$ & $\begin{array}{l}\text { Produção (\%) } \\
(2)\end{array}$ \\
\hline$>0,500$ & 22,82 & 22,19 \\
\hline$>0,340$ & 44,86 & 42,69 \\
\hline$>0,149$ & 30,50 & 30,64 \\
\hline$>0,074$ & 1,49 & 3,28 \\
\hline$<0,074$ & 0,33 & 1,20 \\
\hline
\end{tabular}

Nota: (1) uso de efluente; (2) uso de água.

Após o repouso dos grânulos nos silos, estes foram abastecer as prensas. No dia 25/11/05 os moldes foram preenchidos e prensados (cerca de $300 \mathrm{kgf} / \mathrm{cm}^{2}$ ), produzindo peças com dimensões 15 x $15 \mathrm{~cm}$ e 15 x $20 \mathrm{~cm}$. As peças que saem da prensa são ainda muito frágeis e possuem $6,0 \%$ de umidade ("biscoito cru"). Estas são empilhadas e encaminhadas para secagem na estufa a uma temperatura de aproximadamente $100{ }^{\circ} \mathrm{C}$, para o forno a $1050{ }^{\circ} \mathrm{C} \mathrm{e}$ ao saírem são chamadas de "biscoito queimado".

Em 01/12/05 o biscoito queimado seguiu na linha de esmaltação, onde recebeu esmaltes, aditivos e tintas para a decoração, efetuada por matrizes xerográficas rotativas Após, as peças foram levadas ao forno para sofrerem a segunda queima $\left(1050^{\circ} \mathrm{C}\right)$ por um período de 11 horas, passando ainda pelo controle de qualidade e destinadas à expedição (Figura 3). 


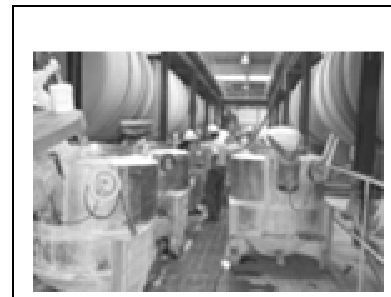

a) Nos moinhos

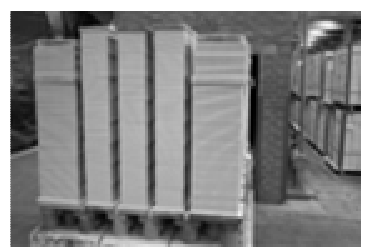

b)Entrada do forno

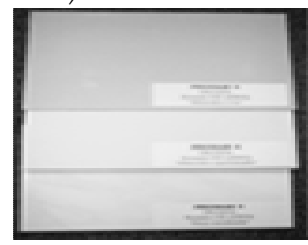

c) Peças a partir do efluente

Figura 3 - INCEPA - Confecção de peças cerâmicas utilizando efluente tratado.

\section{B. Lorenzetti}

$\mathrm{Na}$ Lorenzetti também foi confeccionado fluxograma de demanda de água para se avaliar pontos de maior consumo (Figura 4). A Tabela 5 identifica os processos de consumo de água, alguns dos quais passíveis de serem substituídos por efluente.

Foram coletados cerca de 50 litros de esgoto tratado da ETE Cambuí (Tabela 6) e levados à Lorenzetti no dia 17/06/05, em bombona plástica. $\mathrm{O}$ ensaio foi realizado na "Seção Piloto" onde já se encontravam separadas e pesadas diversas matériasprimas, ditas não plásticas (feldspato, caulim, quartzo), que seriam moídas em moinho de bolas, depois foram adicionados $28 \mathrm{~L}$ de esgoto tratado. O tempo de moagem foi de 12 horas, sendo que os materiais plásticos (argilas) foram previamente preparados com água do lago, manancial da Empresa.

Depois da homogeneização com as argilas, a barbotina foi encaminhada ao filtro-prensa, de modo a formar as pastelas, as quais possuem cerca de $30 \%$ em umidade. O tempo de prensagem é de cerca de uma hora, porém no ensaio demorou menos, indicador de que o esgoto não interferiu negativamente no processo.

As pastelas, primeira forma sólida da massa, devem ter a umidade reduzida para cerca de $20 \%$ antes de entrarem na extrusora e conformar os corpos de prova. Sendo assim, ficaram secando ao ambiente durante uma semana e posteriormente foram colocadas na extrusora (também chamada de maromba) no dia 09/07/05. Na extremidade da extrusora é adaptado um terminal de acordo com o formato e tamanho do corpo de prova que se deseja, permitindo formar tarugos com diâmetro de 1 a 8 $\mathrm{cm}$.

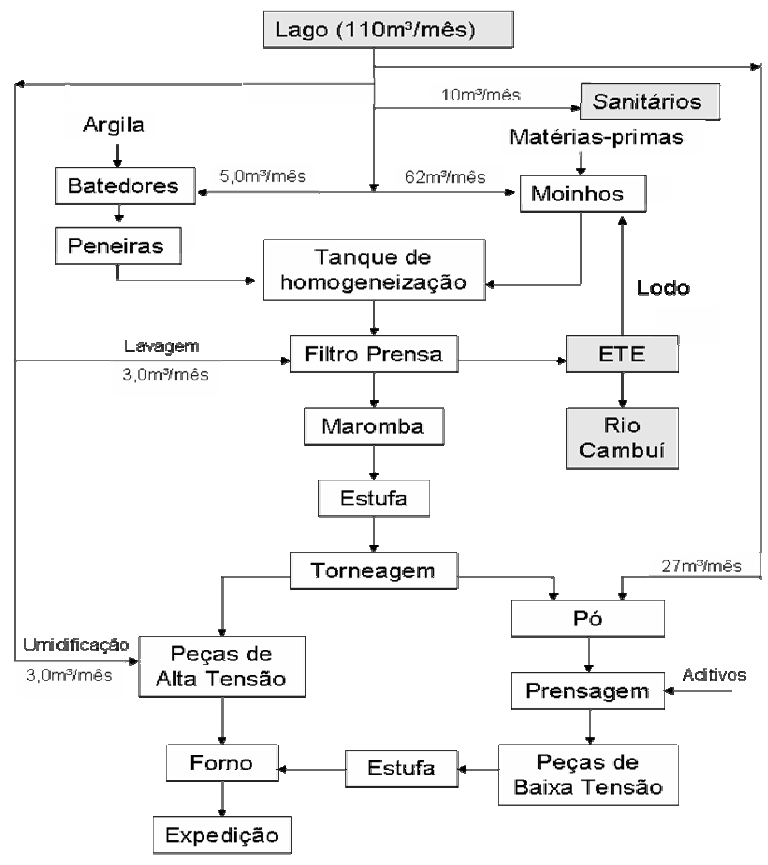

Figura 4 - Fluxograma do consumo de água da Lorenzetti

Tabela 5 - Avaliação dos consumos de água na Lorenzetti

\begin{tabular}{|l|c|}
\hline Uso & $\begin{array}{c}\text { Volume } \\
\left(\mathrm{m}^{3} / \mathrm{mês}\right)\end{array}$ \\
\hline$\bullet$ Administrativo & 2.152 \\
\hline Diretoria / Unidades I e III & 209 \\
\hline Unidade IV & 313 \\
\hline Refeitório & 30 \\
\hline Recursos Humanos e Galvanoplastia & N.C. \\
\hline Expedição/Almoxarifado & 2.704 \\
\hline Total & \\
\hline$\bullet$ Processo Industrial & 62 \\
\hline Moagem & 27 \\
\hline Moldagem de peças de Baixa Tensão & 5 \\
\hline Batedores de argila & 3 \\
\hline $\begin{array}{l}\text { Umidificação das peças de Alta Ten- } \\
\text { são }\end{array}$ & 10 \\
\hline Sanitários & 107 \\
\hline Total & \\
\hline$\bullet$ Outros Usos & 23 \\
\hline Hidrantes e Desengraxe & 3 \\
\hline Limpeza (pisos e equipamentos) & 2.837 \\
\hline Total Geral & \\
\hline
\end{tabular}

Nota: N.C. - Não contabilizado.

Fonte: Bona et al. (2006). 
Após a conformação dos corpos de prova, os mesmos seguiram para secagem por cerca de 4 horas, a temperatura ambiente, foram postos em estufa por 8 horas a $60^{\circ} \mathrm{C}$ e 4 horas a $110^{\circ} \mathrm{C}$ (Figura 5 ).

Tabela 6 - Caracterização do efluente da ETE Cambuí utilizado na Lorenzetti (Data 17/06/2005)

\begin{tabular}{|c|c|c|c|}
\hline Análises & Tipo & Un. & Valor \\
\hline \multirow{15}{*}{$\begin{array}{l}\text { Físico } \\
\text { químicas }\end{array}$} & $\mathrm{Cl}_{2}$ Residual & $\mathrm{mg} / \mathrm{L}$ & 0 \\
\hline & Alcalin. & $\mathrm{mg} / \mathrm{L}$ & 277,14 \\
\hline & $\mathrm{DBOt}$ & $\mathrm{mg} / \mathrm{L}$ & 22,5 \\
\hline & DQOt & $\mathrm{mg} / \mathrm{L}$ & 63 \\
\hline & N-total & $\mathrm{mg} / \mathrm{L}$ & 60,54 \\
\hline & $\mathrm{N}^{-\mathrm{NH}_{3}}$ & $\mathrm{mg} / \mathrm{L}$ & 55,50 \\
\hline & $\mathrm{pH}$ & - & 7,9 \\
\hline & $\mathrm{P}_{-} \mathrm{PO}_{4}$ & $\mathrm{mg} / \mathrm{L}$ & 4,96 \\
\hline & ST & $\mathrm{mg} / \mathrm{L}$ & 361 \\
\hline & SST & $\mathrm{mg} / \mathrm{L}$ & 9 \\
\hline & SSV & $\mathrm{mg} / \mathrm{L}$ & 6 \\
\hline & SDV & $\mathrm{mg} / \mathrm{L}$ & 60 \\
\hline & SSed & $\mathrm{mL} / \mathrm{L}$ & $<0,1$ \\
\hline & Turbidez & UT & 19 \\
\hline & Ferro & $\mathrm{mg} / \mathrm{L}$ & 1,349 \\
\hline \multirow{2}{*}{ Biológicas } & $\begin{array}{l}\text { Coliformes } \\
\text { Totais }\end{array}$ & $\begin{array}{l}\text { NMP/ } \\
100 \mathrm{~m} \\
\mathrm{~L} \\
\end{array}$ & ausentes \\
\hline & Escherichia coli & $\begin{array}{l}\text { NMP/ } \\
100 \mathrm{~m} \\
\mathrm{~L}\end{array}$ & ausentes \\
\hline \multirow{2}{*}{$\begin{array}{l}\text { Temperatu- } \\
\text { ra }\end{array}$} & $\mathrm{Ar}$ & ${ }^{\circ} \mathrm{C}$ & 26 \\
\hline & Amostra & ${ }^{\circ} \mathrm{C}$ & 19,3 \\
\hline
\end{tabular}

O trabalho produziu dois laudos de ensaios físico-químicos dos corpos de prova, um utilizando água do processo habitual (proveniente do lago) e outro utilizando o esgoto da ETE Cambuí (Tabela 7).

Na INCEPA o uso de efluentes na limpeza de pisos e equipamentos pode ser rapidamente incrementado e proximamente em sanitários (vasos sanitários). No entanto este último demandaria investimentos maiores, em projetos e obras. A Tabela 8 apresenta vários cenários com crescente possibilidade de uso.

\section{Substituição das fontes de água}

A configuração atual do consumo de água na Lorenzetti está representada na Figura 6, onde se visualiza o grande consumo oriundo do poço artesiano. Com a proposta de uso de esgoto tratado, pretendeu-se reduzir a captação deste manancial.

Considerando que toda a água destinada ao processo industrial pode ser substituída por esgoto tratado, bem como águas destinadas aos vasos sanitários e hidrantes, obteve-se valores descritos na Figura 7. Segundo Aisse (2000), citando a NBR 7229/93, a contribuição de esgoto por pessoa é de 70L, para fábricas em geral. Como não se pretendeu substituir a água utilizada em lavatórios e chuveiros, considerou-se um total de $60 \mathrm{~L} /$ funcionário, trabalhando numa jornada de 22 dias úteis/mês.

Tabela 7 - Lorenzetti: Resultados do teste de confecção de corpos de prova com efluente da ETE Cambuí

\begin{tabular}{|c|c|c|c|c|}
\hline \multicolumn{2}{|c|}{ Parâmetro } & Un. & Água & Efluente \\
\hline \multicolumn{2}{|l|}{ Massa } & - & Silicosa & Silicosa \\
\hline \multicolumn{2}{|l|}{$\mathrm{Na}_{2} \mathrm{O}$} & $\%$ & 0,69 & 0,67 \\
\hline \multicolumn{2}{|l|}{$\mathrm{K}_{2} \mathrm{O}$} & $\%$ & 3,89 & 3,89 \\
\hline \multicolumn{2}{|c|}{ Peneira \# 200} & $\%$ & 0,12 & 0,10 \\
\hline \multicolumn{2}{|c|}{ Peneira \# 325} & $\%$ & 1,16 & 1,26 \\
\hline \multicolumn{2}{|c|}{ Umidade } & $\%$ & 21,45 & 21,65 \\
\hline \multicolumn{2}{|c|}{ Absorção Água } & $\%$ & 0,00 & 0,00 \\
\hline \multicolumn{2}{|c|}{$\begin{array}{l}\text { Absorção a } \\
\text { Fucsina }\end{array}$} & Visível & NEG & NEG \\
\hline \multicolumn{2}{|c|}{ Deformação } & $0,01 \mathrm{~mm}$ & 0,10 & 0,10 \\
\hline \multicolumn{2}{|c|}{$\begin{array}{l}\text { Densidade } \\
\text { Aparente }\end{array}$} & $\mathrm{g} / \mathrm{cm}^{3}$ & 2,33 & 2,35 \\
\hline \multicolumn{2}{|c|}{$\begin{array}{l}\text { Índice } \\
\text { Piroplástico }\end{array}$} & $\mathrm{mm}$ & $\begin{array}{l}38,8 \\
\text { E-06 }\end{array}$ & $\begin{array}{l}41,6 \\
\text { E-06 }\end{array}$ \\
\hline \multirow{3}{*}{$\begin{array}{l}\text { Módulo } \\
\text { Ruptu- } \\
\text { ra }\end{array}$} & Cru & \multirow{3}{*}{$\mathrm{kgf} / \mathrm{cm}^{2}$} & $\begin{array}{l}54,56 \\
\pm 0,98\end{array}$ & $\begin{array}{l}54,93 \\
\pm 0,98\end{array}$ \\
\hline & $\begin{array}{l}\text { Calci- } \\
\text { nado }\end{array}$ & & $\begin{array}{l}825,81 \\
\pm 19,79 \\
(0,98)\end{array}$ & $\begin{array}{l}828,14 \\
\pm 14,94 \\
(0,98)\end{array}$ \\
\hline & $\begin{array}{l}\text { Com } \\
\text { Vidra- } \\
\text { do }\end{array}$ & & $\begin{array}{l}935,53 \\
\pm 9,63 \\
(1,01)\end{array}$ & $\begin{array}{l}924,87 \\
\pm 6,60 \\
(1,01)\end{array}$ \\
\hline \multicolumn{2}{|c|}{ Perda ao fogo } & $\%$ & 5,48 & 5,48 \\
\hline \multirow{3}{*}{$\begin{array}{l}\text { Retra- } \\
\text { ção }\end{array}$} & Total & \multirow{3}{*}{$\%$} & 12,50 & 12,50 \\
\hline & Queima & & 9,04 & 9,04 \\
\hline & $\begin{array}{l}\text { Seca- } \\
\text { gem }\end{array}$ & & 3,80 & 3,80 \\
\hline
\end{tabular}

Nota: ( ) Diâmetro da barra (corpo de prova. 
Tabela 8 - INCEPA - Resumo do uso de efluente da ETE Cambuí para diversos cenários propostos.

\begin{tabular}{|l|l|l|l|l|l|l|l|l|}
\hline \multirow{2}{*}{ Fontes } & \multicolumn{2}{l|}{ Atual } & \multicolumn{2}{l|}{ Opção 1} & \multicolumn{2}{l|}{ Opção 2} & \multicolumn{2}{l|}{ Opção 3 } \\
\cline { 2 - 10 } & $(\%)$ & $\left(\mathrm{m}^{3} / \mathrm{mês}\right)$ & $(\%)$ & $\left(\mathrm{m}^{3} / \mathrm{mês}\right)$ & $(\%)$ & $\left(\mathrm{m}^{3} / \mathrm{mês}\right)$ & $(\%)$ & $\left(\mathrm{m}^{3} / \mathrm{m}^{\mathrm{s}}\right)$ \\
\hline Lago & 66 & 15.000 & 46 & 10.507 & 63 & 14.173 & 43 & 9.680 \\
\hline Reúso Interno & 29 & 6.600 & 29 & 6.600 & 29 & 6.600 & 29 & 6.600 \\
\hline Esgoto Cambuí & 0 & 0 & 22 & 4.936 & 5 & 1.241 & 27 & 6.177 \\
\hline Sanepar & 5 & 1.070 & 3 & 627 & 3 & 656 & 1 & 213 \\
\hline Total & 100 & 22.670 & 100 & 22.670 & 100 & 22.670 & 100 & 22.670 \\
\hline
\end{tabular}

Nota: $\quad$ Opção 1 - utilizado na limpeza; Opção 2 - utilizado em banheiros;

Opção 3 - utilizado na limpeza e nos banheiros.

Fonte: Göhringer (2006)

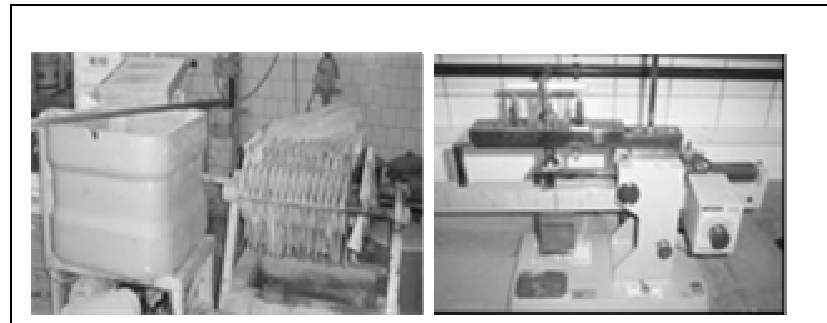

a)Instalação Piloto; b)Ensaio Ruptura;

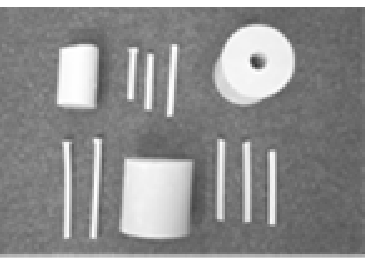

c) Corpos de prova com efluente.

Figura 5 - Lorenzetti - Ensaio para confecção de peças cerâmicas utilizando efluente tratado.

Consumo de água na Lorenzetti - atual $\left(\mathrm{m}^{3} / \mathrm{mês}\right)$

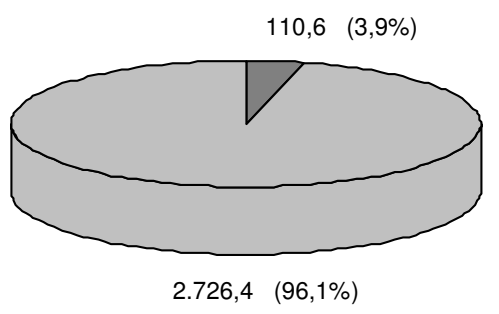

$\square$ Água do Lago $\mathbf{A}$ gua do Poço

Figura 6- Consumo de água na Lorenzetti - cenário atual

\section{DISCUSSÃO}

A avaliação do consumo de água nas empresas estudadas revelou que a quantificação deste insumo não é totalmente conhecida. Foram necessárias medições complementares de vazões e volumes para a conclusão do balanço hídrico.

No processo industrial destacou-se o uso nos moinhos, que sinalizou para a condução dos experimentos práticos com o efluente. No entanto, recomenda-se aprofundar as discussões e internalizar a prática do reúso da água nas empresas.

Quanto à utilização do efluente na confecção de material cerâmico na INCEPA (azulejos), os três ensaios realizados sugerem a necessidade de análise preliminar do efluente, para a adequada incorporação de aditivos e correção do $\mathrm{pH}$ na massa. Este descuido conduziu às dificuldades citadas no ensaio 2. Denotou-se ser importante comunicar previamente ao usuário que a qualidade do efluente, para alguns sistemas de tratamento, nem sempre é constante ao longo do dia, variando também sazonalmente. Cumpre citar que o efluente utilizado apresentava ausência de coliformes. A continuidade dos ensaios resultou na confecção de peças de igual qualidade àquelas produzidas com água de uso corrente, o que comprovou a possibilidade do reúso sem comprometer o produto acabado, pois as peças foram comercializadas normalmente.

Atualmente a água residuária proveniente da lavagem do material cerâmico e de parte do processo industrial passa por um tratamento físicoquímico, dentro da própria indústria, e depois é reusada no processo industrial. Isto revela certa facilidade para se continuar a internalizar a cultura do reuso da água.O uso do efluente na Lorenzetti, conduzido na Seção Piloto, gerou laudos técnicos 
que mostraram a adequação do efluente como insumo para a fabricação dos corpos de prova. Estes, submetidos aos ensaios específicos, não apresentaram diferenças significativas, com os corpos de prova confeccionados com água (uso industrial padronizado). Conforme se pôde constatar, mesmo existindo diferenças nas características físico-químicas entre a água do lago e o esgoto tratado da ETE Cambuí, este poderá ser utilizado para a preparação da massa nos moinhos destinada à confecção de peças eletro-cerâmicas, dado que não houve interferência na qualidade do produto final.

Consumo de água na Lorenzetti - estimado $\left(\mathrm{m}^{3} / \mathrm{mês}\right)$

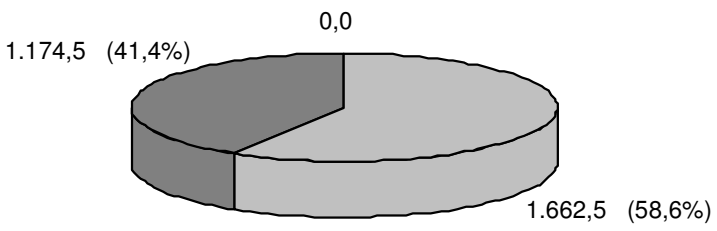

$\square$ Água do Lago $\square$ Água do Poço $\square$ Esgoto Tratado ETE Cambuí

Figura 7 - Consumo de água na Lorenzetti cenário proposto

A proposta de substituição das fontes de abastecimento de água foi de caráter especulativo, pois haveria a necessidade de investimentos das empresas no que se refere ao sistema duplo de abastecimento dos banheiros. Quanto à produção, deveria ser avaliada a possibilidade de se utilizar a instalação atual. Outrossim, ainda não existe uma política de venda de esgoto tratado para indústrias por parte da SANEPAR.

\section{CONCLUSÕES E RECOMENDAÇÕES}

Após os testes realizados junto às Empresas Incepa e Lorenzetti, concluiu-se que é possível utilizar o efluente tratado e desinfetado da ETE-Cambuí para fins não potáveis, na confecção de peças cerâmicas referendado ainda pelos técnicos industriais.

No caso da INCEPA, conforme citado pela Opção 3 da Tabela 8 (cenário otimista), obteve-se que de toda a água utilizada pela empresa, $27 \%$ poderia ser esgoto tratado, reduzindo a captação do lago de $66 \%$ para $43 \%$ e o fornecimento de água potável de $5 \%$ para $1 \%$.

Para a Lorenzetti, observou-se que é possível substituir a água por esgoto tratado, totalizando $41,4 \%$ do total de água utilizada, não sendo mais necessário extraí-la do lago da empresa para o processo industrial Seria reduzido o volume do uso da água do poço artesiano, dos atuais $96,1 \%$ para $58,6 \%$.

Esta prática quando concretizada em escala industrial junto às empresas, contribuirá para aliviar a demanda de água de mananciais do Município de Campo Largo.

\section{AGRADECIMENTO}

Os autores agradecem a SANEPAR e ao PROSAB/CTHIDRO, através da FINEP, CNPq e CEF, o apoio demonstrado ao longo do desenvolvimento dos trabalhos. Às empresas, INCEPA e Lorenzetti, pela divulgação irrestrita de informações necessárias, disponibilidade em realizar os ensaios e suporte técnico.

\section{REFERÊNCIAS}

AISSE, M. M. Sistemas Econômicos de Tratamento de Esgotos Sanitários. Rio de Janeiro, ABES. 2000.

AISSE, M.M.; JÜRGENSEN, D.; LOBATO, M.B.; ALÉM SOBRINHO, P. Avaliação do Sistema Reator Ralf e Flotação por Ar Dissolvido no Tratamento de Esgoto Sanitário. In: Sanare. 17 (17): 49-58. Jan/jun 2002.

APHA; AWWA; WEF. Standard Methods for Examination of Water and Wastewater. 20 ${ }^{\mathrm{a}}$ edição. Washington, D.C., APHA. 1998.

BONA, A; BERGER, E.; AISSE, M. M. Uso de Efluente de Estação de Tratamento de Esgoto Sanitário para Fins Não Potáveis na Empresa Lorenzetti. Relatório do Estudo. Curitiba, PUCPR. 2006.

CROOK, J.; OKUN, A. D. Reuso da água para fins não potáveis: seu lugar no gerenciamento de recursos hídricos. In: Revista DAE. 160: 15-18. Jan/jun. 1991.

GÖHRINGER, S. S. Uso Urbano Não Potável de Efluentes de Estação de Tratamento de Esgoto Sanitário: Estudo de Caso Município de Campo Largo. Curitiba, PUCPR. Dissertação (Mestrado). 2006.

HESPANHOL, I. Potencial de reúso de água no Brasil: agricultura, indústria, município e recarga de aqüífero. In: 
Reúso de Água. MANCUSO \& SANTOS (organizadores). São Paulo, Manole, 2003. p. 40-46.

SEMURA, K. A.; RICCITELLI, M.; GONÇALVES, C.M. Estudo para Implantação de Reúso e Proposição de Parâmetros de Qualidade para Usos Urbanos Não Potáveis a Partir das ETE's da RMSP. 23ํㅡㄹ Congresso Brasileiro de Engenharia Sanitária e Ambiental. Anais. Campo Grande. 2005.

\section{Use of Sanitary Effluent in the Ceramics Industry}

\section{ABSTRACT}

This article discusses the non-potable use of the Cambui WWTP effluent in ceramics industries located in Campo Largo-PR. The Cambui WWTP of SANEPAR receives sanitary wastes from the sewers, with the use of a treatment flowchart, including RALF reactors, physicalchemical treatment by means of flotation by dissolved air and disinfection. Its design outflow is $100 \mathrm{l} / \mathrm{s}$, which was chosen because of effluent quality and location. The effluents were used in two industries, INCEPA and Lorenzetti; both work with ceramic products and are located near the WWTP. The work begins by examining non-potable water demand, highlighting consumption in the mills. INCEPA tested the effluent use on an industrial scale, which led to the production of ready-to-sell ceramic pieces (tiles and floors). Lorenzetti performed pilot scale tests, using water and effluent in parallel. The test specimens produced were submitted to specific assays for ceramic items to be used with electricity, and showed identical results. The conclusion is: non-potable use of the treated and disinfected Cambui WWTP effluents is possible, according to the "sources substitution" concept. Other configurations were also created, allowing the use of effluents for different ends, in some cases attaining a $41.4 \%$ rate of effluent.

Key-words: Ceramics industries; non potable reuse; sanitary effluent; water reuse. 